\title{
What are the experiences of men affected by prostate cancer participating in an ecological momentary assessment study?
}

\author{
PATERSON, C., PRIMEAU, C., LAUDER, W.
}


Title: What are the experiences of men affected by prostate cancer participating in an ecological momentary assessment study?

Authors: Paterson, C., PhD; Primeau, C., PhD; Lauder, W., PhD.

Author Affiliations: School of Nursing and Midwifery, Robert Gordon University (Drs Paterson and Primeau) and School of Nursing and Midwifery, University of Highlands and Islands (Prof Lauder)

Correspondence: Catherine Paterson, PhD, Robert Gordon University, School of Nursing and Midwifery, Garthdee, Aberdeen, AB10 7QG, c.paterson15@rgu.ac.uk

Key words: prostate cancer; ecological momentary assessment; qualitative; real time; quality of life; lived experience.

The authors have no funding or conflicts of interest to disclose. 


\section{Background}

Within the cluster of self-report methodologies, ecological momentary assessment (EMA) is a method used in health services research whereby a participant repeatedly reports on affect, behaviours, symptoms and cognitions as they occur in real time in the participants natural environment. However, little is known about the impact of participating in an EMA study on individuals’ experiences who are affected by prostate cancer.

\section{Objectives}

To explore the lived experiences of men affected by prostate participating in an EMA study and assess whether their participation in EMA alters their representation of their condition.

\section{Methods}

Participants (12n) were purposively recruited from two university teaching hospitals in Scotland. Semi-structured interviews were conducted with men affected by prostate cancer following the completion of EMA data collection. Data were analysed using thematic analysis.

\section{Results}

The lived experience of prostate cancer included six superordinate themes: isolation in the healthcare system, lack of shared care plans, informational support, coping with prostate cancer, fear of death and dying, and vocational rehabilitation. The organising theme electronic diary as an intervention included four superordinate themes: changing self-management behaviours, habitual experience, changing perceptions and diary in daily life.

\section{Conclusion}

We observed that men participating in the EMA study described several methodological complexities which needs addressed through future research. 


\section{Clinical Implications}

Importantly, there is a need for the health system to prioritise research and develop a more holistic approach to prostate cancer care in line with men preferences and needs in the future. 


\section{Introduction}

Prostate cancer is the most prevalent type of cancer in men ${ }^{1}$ and its associated treatments can have a profound negative impact on health-related quality of life (HRQoL) ${ }^{2}$. Moreover, men can experience a range of unmet supportive care needs ${ }^{3}$ mainly related to intimacy, physical, psychological and informational needs ${ }^{4-6}$ which can inhibit recovery of HRQoL . There is an undisputed requirement for accurate and reliable assessments of quality of life in this patient group as the existing evidence base is entirely limited to retrospective self-report evaluations ${ }^{2}$. Within the cluster of self-report methodologies, ecological momentary assessment (EMA) refers to a collection of methods used in health services research by which a participant repeatedly reports on affect, behaviours, symptoms and cognitions as they occur in real time in the participants natural environment, ideally using an electronic diary ${ }^{7}$. There are several advantages of using EMA over traditional self-report assessments. Firstly, EMA captures present experiences rather than relying on summary ratings of a particular construct, or reliance on the participants memory over weeks or months, hence it minimises recall bias. Secondly, EMA is conducted in naturalistic social and environmental contexts for participants, thus increasing the ecological validity in the assessment. Thirdly, EMA involves multiple repeated assessments over time, and provides rich detailed information on the temporal experiences of patients ${ }^{7,8}$. Ecological momentary assessment has now been applied to assess a range of health-related symptoms and behaviours in patients with pain ${ }^{9}$, tobacco behaviours ${ }^{10}$, asthma ${ }^{11}$, cancer ${ }^{12}$, diabetes ${ }^{13}$ and alcohol use ${ }^{14}$. There is a dearth of research which has applied EMA to men affected by prostate cancer ${ }^{15}$ and indeed people affected by cancer in general ${ }^{12}$. However, little is known about the impact of participating in an EMA study in individuals affected by prostate cancer. This approach to real time monitoring provides an assessment of patient's moment-to-moment emotional, behavioural and cognitive experiences that could contribute to a better understanding of supportive care needs and an evaluation of the correlates and predictors of HRQoL over time. While the benefits of applying this methodology in health services research is clear, it is unknown if men participating in an EMA study are reminded daily of their diagnosis and how this might affect their recovery ${ }^{16}$. Moreover, real time approaches to data collection may be exposed to several methodological complexities, namely 
reactance, habituation, increased complexity and gradual entrainment, which may pose a threat to the validity of electronic diary data ${ }^{17}$. Reactance occurs when the participant's behaviour changes because of completing the diary. A reactive measure is one that changes unintentionally the phenomenon which it is designed to measure ${ }^{18}$. Habituation has been described as the development of habitual responses when completing the electronic diary, that is to say, a tendency to skim over questions that rarely apply to the participants experience ${ }^{19}$. Repeated exposure to diary questions over time may change a participant's understanding of a particular construct for example, increased complexity or gradual entrainment. Increased complexity refers to the development of a more advanced understanding of a construct due to repeated exposure to the surveyed domain of interest. Whereas, gradual entrainment is described as the participants changing their conceptualisation of their illness to fit with those measured in the electronic diary ${ }^{19}$. Importantly, to date no study has explored these potential methodological complexities of conducting an EMA study in men affected by prostate cancer. Therefore, this study aimed to address the following research questions:

- What are the lived experiences of men affected by prostate cancer participating in an EMA study?

- Does the experience of men affected by prostate cancer providing real-time data using an electronic diary alter their representation of their condition?

\section{Methods}

We conducted an EMA study in men affected by prostate cancer ${ }^{15}$ and reported this according to the Checklist for Reporting EMA Studies (CREMAS) ${ }^{20}$. Here we present the in-depth qualitative study. Ethical approval was obtained (10/S1402/7) following review by the North East of Scotland NHS Ethics Committee. 


\section{Participants}

Participants from two teaching hospitals in Scotland were invited to take part in this research study using the following inclusion criteria: confirmed diagnosis of prostate cancer (PCa) all stages and treatments, ability to read and write English, and able to give informed consent. Exclusion criteria were those individuals unable to meet the inclusion criteria or those patients identified by their clinical care team to be physically or psychologically unfit to take part in the study. Recruitment took place at two hospital out-patient settings, and demographic and clinical data were collected.

\section{Electronic dairy}

Researchers had to develop diary instruments ${ }^{4}$ as there are no standardised instruments available for electronic behavioural diaries. The electronic diary as a small handheld Personal Digital Assistant (PDA). The contents of the diary questions were mapped to the constructs of the questionnaires (see Table 1 for the diary structure overview) in the prospective longitudinal study ${ }^{21,22}$ and informed by prostate cancer patients and clinicians comments. The diary structure included seven questions at the standard entry, 12 questions at the end-of-day entry, and five questions at incident entry. The question items presented on the diary consisted of a 'standard entry' (completed three times per day), an 'endof-day entry' (completed once per day) and an 'incident entry' that could be completed at any-time throughout the one-month period of data collection. The diary entries were prompted by an audio alarm at set intervals throughout the data collection and the participant's recorded their entries digitally using the PDA device. After the one-month period of data collection, the electronic diary was collected by the researcher and the data from the PDA was transferred securely to a password protected data base.

\section{Data collection}

Exploratory purposive semi-structured interviews were conducted using a topic guide informed by existing literature ${ }^{15,17,19}$ and the research question (See Table 2). This interview guide focused on participants' experience of providing multiple real time daily entries using an electronic diary and their experience of living with prostate cancer. Purposive sampling of the interviewees ensured maximum variation by patients' age (range $=51-75$ years), socioeconomic background (ranging from 1 [most 
deprived] to 5 [least deprived]), cancer stage (localised, locally advanced and metastatic disease) and treatments (curative to palliative intent) and the prevalence of the number of existing co-morbidities (range $=0-5$ ). The study sample was designed to enable the researchers to explore some diversity in the men's experiences. Field notes were written immediately following the interviews to record any conversations before and after the formal interview. Data saturation was reached when no new information related to the experience of completing the electronic diary or themes were identified during the interview process.

\section{Rigour}

We followed the concepts of credibility, transferability, dependability, and confirmability ${ }^{23}$ to ensure rigor of the study. We audio recorded thoughts, impressions, and took reflective notes immediately after each interview for credibility. The interview data were also checked by peers to verify the identified themes. We provided a thorough description of the study sample and setting in considering the transferability of the study findings. We also maintained an audit trail as the study progressed in terms of decision making. Open-ended and repetitive questioning strategies were used during the interviews and discussions during the data interpretation and verification process of confirmability.

\section{Description of the interview}

All semi-structured interviews were audio recorded with the patient's written informed consent by the first author. The interviews were conducted in the participants' homes or in a quite private room in a cancer care centre. The interviews began with a non-directive, open-ended question to encourage the participants to speak about their experiences of completing the real time electronic diary and were invited to discuss other aspects of their prostate cancer experience that they considered were important. Open-ended probe questions were also used to elicit greater detail and understanding of the experiences shared by participants.

\section{Data Analysis}


The semi-structured interviews lasted a mean 50.1 minutes (SD 11.2; range 33.4-96.1 minutes). Recordings were transcribed using an 'orthographic' transcript - a verbatim account of all verbal and nonverbal e.g., silences, utterances, and cross-checked for accuracy, and identifying information was removed. One of the authors coded all the interviews, and coding was subsequently verified by peers, when needed, to ensure a close match. Thematic analysis ${ }^{24}$ was used to examine commonalities and differences within and between the transcripts. Themes were derived inductively from the data by reading and re-reading the interview narratives and from this developing an understanding of men's lived experience through their words. Broad themes were identified, and an electronic matrix display (in Microsoft Excel), which included original links to the data facilitated a transparent account of how themes were derived. Transcripts were coded iteratively with constant comparison between the codes generated and the data to ensure that consistent and diverging responses were incorporated. Triangulation strategies included comparison of the study data collected from the EMA ${ }^{15}$. Exemplar responses were identified across transcripts to illustrate and confirm the labelling of themes. Reporting of data is consistent with consolidated criteria for reporting qualitative studies (COREQ) guidelines ${ }^{25}$.

\section{Findings}

In total, 12 participants completed the EMA study and all participants consented to being interviewed (see Table 3) after completing the one-month real time data collection. Thematic analysis identified two organising themes: lived experience and electronic diary as an intervention. The first organising theme reflected men's experience living with prostate cancer and within this there were six superordinate themes. The second organising theme captured men's experiences of taking part in the EMA study and within this there were four superordinate themes. Figure depicts the coding structure, Table 4 and 5 provides illustrative quotes for each of the superordinate themes.

\section{Lived experience}

The lived experience of prostate cancer included six superordinate themes: isolation in the healthcare system, lack of shared care plans, informational support, coping with prostate cancer, fear of death and dying, and vocational rehabilitation (see Table 4). 


\section{Isolation in the healthcare system}

Many of the men articulated a sense of isolation in the healthcare system. Difficulties related to safely navigating through the system with a limited access to specialist nursing care. Men expressed concerns related to a fragmented pathway and a lack of continuity of communication and care in the community setting. Moreover, men who did require psychological counselling experienced significant and unacceptable delays in accessing intervention and support. Some men were left with a sense of abandonment.

\section{Lack of shared care plans}

Most men experienced challenging symptoms to self-manage because of their prostate cancer treatments. Symptoms related to urinary, bowel and sexual dysfunction and grappling with the sideeffects of ADT. Men described a lack of shared decision making and a lack of documented care plans to help them confidently self-manage their condition. One man diagnosed with localised prostate cancer articulated difficulties in his complex decision-making process with his surgeon in opting for active surveillance.

\section{Informational support}

Men were given various levels of written information. Some were provided comprehensive information booklets and other with some basic leaflets. Most men wanted to have the opportunity to discuss information verbally with a healthcare professional. Some of the men expressed that the electronic diary changed their conceptualisation of what support they actually needed over time. Men expressed that due to a lack of information to help them manage their condition this impacted upon their ability to cope with prostate cancer.

\section{Coping with prostate cancer}


Men used a variety of coping strategies which predominately related to avoidance in relation to their cancer. For the two men undergoing active surveillance for their localised prostate cancer they spoke about avoidance in thinking about living with an untreated cancer. Most men had a sense of optimism and they were the "lucky" ones compared to other men affected by this disease. Whereas, men living with incurable metastatic prostate cancer struggled to cope with the fear/uncertainty for the future and one man described his disease as conceivable bad habit in his body.

\section{Fear of death and dying}

Men spoke about their concerns about their prognosis across all stages of prostate cancer. Some of the men described that their fears were heightened due to reading written information and the sharing of experiences from other patients. Some described the need to think about the "what if's" to help them psychologically and practically prepare for next steps in an uncertain future.

\section{Vocational rehabilitation}

Some men spoke about difficulties and a lack of support in returning to paid employment following their prostate cancer treatment. Work was important for these men to help them gain confidence, maintain their identity and help to regain a sense of normality. Men described a lack of employment support in relation to the safe assessment of work-related duties, and a lack of psychological support in the work place.

\section{Electronic Diary as an Intervention}

The organising theme electronic diary as an intervention included four superordinate themes: changing self-management behaviours, habitual experience, changing perceptions and diary in daily life.

\section{Changing self-management behaviours}

Men articulated that they modified their self-management behaviours and cognitions due to participating in the EMA study. Men described obtaining ideas by extracting information from the daily diary questionnaire. Modifications to self-management behaviours over the one-month period of 
data collection included: sharing thoughts and feelings, opting for decaffeinated alternatives and reduction of alcohol intake to alleviate urinary symptoms, diet modifications for bowel symptoms and the commencement of a written toileting diary to monitor function post-radiotherapy to share with their clinical team.

\section{Habitual experience}

Many men described habitual approaches to completing the daily electronic diary over the one-month of data collection. Men found the questions repetitive and that they developed an awareness and understanding of what the questions were going to be, and how they would answer them before completing the diary entry. Some patients described strategies of skimming over the questions that rarely applied to them and other men carefully reading the diary questions at each entry.

\section{Changing perceptions}

Interestingly some men described that their conceptualisation of their condition changed due to repeated exposure to the diary questions. Some men changed their conceptualisation of their illness to be in keeping with the diary to some extent. Other men developed a sense of optimism in that they perceived that other patients were experiencing more distressing symptoms than themselves due to repeated exposure of the HRQoL surveyed domain in the diary.

\section{Diary in daily life}

All men articulated that they derived benefit in completing the electronic diary and would recommend it to another patient. Men found it helpful for altruistic reasons and some perceived that the diary was a psychological support to them in their daily lives. Men described that they found it helpful in sharing their experiences without having to verbalise their concerns aloud. Moreover, men also described that completing the electronic diary quickly became embedded in their daily lives and social routines. Surprisingly, not one man found the diary a burden and men did not perceive any negative aspects of completing the electronic diary several times daily. Irrespective of age all men perceived the use of mobile technology as an integral part of modern life and society. 


\section{Discussion}

This study extends previous research ${ }^{3,4,15,26}$ in understanding the lived experience of prostate cancer, but also provides the first unique insights into the methodological complexities of participating in an EMA study in men affected by prostate cancer. In keeping with previous research ${ }^{2,3}$, men in this study shared a range of profound decrements in quality of life and a range of unmet supportive care needs in routine service delivery. Men also shared concerns about issues related to vocational rehabilitation and returning to paid employment following treatment for their prostate cancer. Returning to work for people affected by cancer is a key priority ${ }^{27}$, however there are limited services available to support men to remain in or return to work, and no associated trials to assess their impact in this population ${ }^{28}$. It was clear from the experiences shared in this study that vocational rehabilitation is needed, and needs addressed through future research and carefully designed interventions.

Men experienced issues related to a lack of shared care planning and isolation in the health care system. These are not new emergent findings ${ }^{29}$ but affirms that these issues are persistently related to a lack of patient awareness of available resources to support self-management ${ }^{30}$ and a lack of informational support around the following aspects of self-management: management of side-effects, lack of awareness of appropriate signposting to healthcare professionals, and support for sexual recovery ${ }^{31,32}$.

To our knowledge this is the first novel study which has explored the patients' perspective in their experience of participating in an EMA study and the impact it had on their daily lives. Due to recent eHealth drivers in healthcare we have observed an exponential growth in digitalised EMA studies in long-term conditions ${ }^{9,17,33}$ however no study has of yet explored patients' own experience of participating in an EMA study. We observed that men derived benefit from tracking their real time data for different reasons. Some men found it helpful to periodically check their own progress and others used the data for real-time decisions about changing their self-management behaviours. A reactive measure is one that changes the phenomenon it is designed to assess. This is desirable if measurement 
occurs as part of an intervention aimed at changing behaviour but is problematic when measurement over time is used only to assess the phenomenon of interest. Elsewhere, several studies have tested the reactivity of the EMA diary in participants with chronic pain ${ }^{8,34-36}$ and alcohol misuse ${ }^{37}$. Reactivity of the EMA approach has been examined using both paper-based ${ }^{36,37}$ and electronic-based ${ }^{34,35}$ approaches and these authors have claimed that they did not observe any reactive effects. There are a few shortcomings in these studies. Participants who used a paper-and-pencil recording diary may have fabricated their answers by forward and backfilling their diaries ${ }^{36,37}$ and may have introduced retrospective memory recall. Moreover Cruise's study ${ }^{36}$ had 50\% missing data in the participants' paper-based diaries and, therefore at risk of a type two statistical error. For the electronic diary studies 34,35 they were biased in favour of white females, and limits the generalisability of the findings to men and to patients from different ethnic groups and clinical groups. We also argue that it is possible that reactive effects of the EMA approach may have been masked by their study designs ${ }^{34-37}$. Noteworthy all these studies ${ }^{34-37}$ had data collection schedules which was limited to either one week or two weeks and as such these durations may not have been long enough to detect reactive effects. This schedule is in contrast to our study which has a data collection schedule for a total period of one-month ${ }^{15}$. Finally, it is important to acknowledge the limitations of the operational definition of reactivity. Commonly, a lack of reactive effect for daily pain scores and alcohol intake was defined by the absence of any statistically significant change in the variable of interest over time ${ }^{34,35}$. We contend that using such criteria is problematic for several reasons to evaluate reactivity to the EMA diary. Patients' pain can change due to several factors including: regression to the mean, treatment modifications, and altered health states over time. Testing reactivity in this way assumes that reactivity is a gradual build-up of the effect of the EMA diary, whereas reactive effects may happen on the first day of data collection and subsequently remain unchanged. Importantly, all studies ${ }^{34-37}$ measured reactivity as a gradual change in average scores of the variable of interest over time. Here we provide for the first-time in-depth qualitative accounts to advance our understanding of reactivity in the EMA methodology.

A further theme which emerged in the qualitative findings was related to habitual experience for the men in the completion of their diary entries. However, no research has explored the influence of 
habituation on diary data collection elsewhere ${ }^{18}$ and would require future research to confirm of refute our findings. We also found that repeated exposure to the surveyed domains facilitated the process of developing an understanding of their disease, and this has been reported elsewhere ${ }^{16}$.

Overall, participation in the EMA was highly acceptable and men derived benefit in the sharing of their experiences and learned new strategies to self-care. Men also benefited from being able to share their concerns without having to verbalise them out loud. Given the persistent unmet supportive care needs in routine service delivery ${ }^{3,4,6,30}$, we propose that there is a need to change the conceptualisation of our service provision to deliver what men actually want, rather than revisiting services that already exist and are not meeting men's needs. We would suggest that EMA in prostate cancer care may serve as a future intervention platform and worthy of research investment with high quality and well-designed trials.

\section{Limitations}

The limitations in this study include the cross-sectional qualitative interview design. Future research using a prospective case study design will add further depth to our understanding of men's experiences in this area. We had several strengths that included a transparent and robust study method and involvement of men with varied clinical and demographic backgrounds, as such our data can be transferable across the Scottish setting.

\section{Conclusion}

We observed that men participating in the EMA study described several methodological complexities, namely habitation and reactivity which needs addressed through future research. Importantly, there is a need for the health system to prioritise research and develop a more holistic approach to clinical prostate cancer care in line with men preferences and needs in the future. 


\section{References}

1. Houston KA, King J, Li J, Jemal A. Trends in Prostate Cancer Incidence Rates and Prevalence of Prostate Specific Antigen Screening by Socioeconomic Status and Regions in the United States, 2004 to 2013. The Journal of Urology. 2018;199(3):676-682.

2. Adam S, Feller A, Rohrmann S, Arndt V. Correction to: Health-related quality of life among long-term ( $\geq 5$ years) prostate cancer survivors by primary intervention: a systematic review. Health and Quality of Life Outcomes. 2018;16(1):162.

3. Paterson C, Robertson A, Smith A, Nabi G. Identifying the unmet supportive care needs of men living with and beyond prostate cancer: A systematic review. European Journal of Oncology Nursing. 2015;19(4):405-418.

4. Paterson C, Kata G, Nandwani G, Daschaudhury D, Nabi G. Unmet supportive care needs of men with locally advanced and metastatic prostate cancer on hormonal treatment: A mixed methods study. Cancer Nursing: An International Journal for Cancer Care. 2017;40(6):497507.

5. Paterson C, Nabi G. A Model of Consultation in Prostate Cancer Care: Evidence From a Systematic Review. Cancer Nurs. 2016.

6. Primeau C, Paterson, C, Nabi, G. A qualitative study exploring models of supportive care in men and their partners/caregivers affected by metastatic prostate cancer Oncology Nursing Forum. 2017;1;44(6):E241-E249.

7. Shiffman S, Stone AA, Hufford MR. Ecological momentary assessment. Annual Review Of Clinical Psychology. 2008;4:1-32.

8. Stone AA, Schwartz JE, Broderick JE, Shiffman SS. Variability of momentary pain predicts recall of weekly pain: a consequence of the peak (or salience) memory heuristic. Personality \& Social Psychology Bulletin. 2005;31(10):1340-1346.

9. May M, Junghaenel DU, Ono M, Stone AA, Schneider S. Ecological Momentary Assessment Methodology in Chronic Pain Research: A Systematic Review. The Journal of Pain. 2018;19(7):699-716. 
10. Soong A, Chen JC, Borzekowski DL. Using Ecological Momentary Assessment to Study Tobacco Behavior in Urban India: There's an App for That. JMIR research protocols. 2015;4(2):e76.

11. Jones DR, Johnson JA, Graham-Engeland JE, Park CL, Smyth JM. Is Perceived Growth Associated with Momentary Indicators of Health and Well-Being in People with Asthma or Rheumatoid Arthritis? Applied Psychology: Health and Well-Being. 2018;10(2):254-271.

12. Shiyko MP, Siembor B, Greene PB, Smyth J, Burkhalter JE. Intra-individual study of mindfulness: ecological momentary perspective in post-surgical lung cancer patients. Journal of Behavioral Medicine. 2018.

13. Zajdel M, Helgeson VS, Seltman HJ, Korytkowski MT, Hausmann LRM. Daily Communal Coping in Couples With Type 2 Diabetes: Links to Mood and Self-Care. Annals of Behavioral Medicine. 2018;52(3):228-238.

14. Jones A, Tiplady B, Houben K, Nederkoorn C, Field M. Do daily fluctuations in inhibitory control predict alcohol consumption? An ecological momentary assessment study. Psychopharmacology. 2018;235(5):1487-1496.

15. Paterson C, Jones M, Rattray J, Lauder W, Nabi G. What is the mechanism effect that links social support to coping and psychological outcome within individuals affected by prostate cancer? Real time data collection using mobile technology. European Journal of Oncology Nursing. 2015;17(6):150-158.

16. Ancker JS, Witteman HO, Hafeez B, Provencher T, Van de Graaf M, Wei E. "You Get Reminded You're a Sick Person”: Personal Data Tracking and Patients With Multiple Chronic Conditions. J Med Internet Res. 2015;17(8):e202.

17. Trull TJ, Ebner-Priemer UW. Using Experience Sampling Methods/Ecological Momentary Assessment (ESM/EMA) in Clinical Assessment and Clinical Research: Introduction to the Special Section. Psychological assessment. 2009;21(4):457-462.

18. Bolger N, Davis A, Rafaeli E. Diary methods: Capturing life as it is lived. Annual review of psychology. 2003;54(1):579-616. 
19. Jones M, Johnston D. Understanding Phenomena in the Real World: The Case for Real Time Data Collection in Health Services Research. Journal of Health Services Research \& Policy. 2011;16(3):172-176.

20. Liao Y, Skelton K, Dunton G, Bruening M. A Systematic Review of Methods and Procedures Used in Ecological Momentary Assessments of Diet and Physical Activity Research in Youth: An Adapted STROBE Checklist for Reporting EMA Studies (CREMAS). J Med Internet Res. 2016;18(6):e151.

21. Paterson C. Exploring prostate cancer survivors'self-management behaviours and social supportive experiences using questionnaires and electronic behavioural diaries: Does social support buffer the relationship between coping and health-related quality of life? Dundee: School of Nursing and Midwifery, University of Dundee; 2013.

22. Paterson CIE, Robertson AF, Nabi G. Exploring prostate cancer survivors self-management behaviours and examining the mechanism effect that links coping and social support to health-related quality of life, anxiety and depression: A prospective longitudinal study. European Journal of Oncology Nursing. 2014;19(2):120-128.

23. Schwandt TA, Lincoln YS, Guba EG. Judging interpretations: But is it rigorous? trustworthiness and authenticity in naturalistic evaluation. New Directions for Evaluation. 2007;2007(114):11-25.

24. Braun V, Clarke V, Terry G. Thematic analysis. Qual Res Clin Health Psychol. 2014;24:95114.

25. Tong A, Sainsbury P, Craig J. Consolidated criteria for reporting qualitative research (COREQ): a 32-item checklist for interviews and focus groups. International Journal for Quality in Health Care. 2007;19(6):349-357.

26. King AJL, Evans M, Moore THM, et al. Prostate cancer and supportive care: a systematic review and qualitative synthesis of men's experiences and unmet needs. European Journal of Cancer Care. 2015;24(5):618-634. 
27. Fong CJ, Murphy KM, Westbrook JD, Markle MM. Psychological Interventions to Facilitate Employment Outcomes for Cancer Survivors: A Systematic Review and Meta-Analysis. Research on Social Work Practice. 2015;28(1):84-98.

28. Kyle RG, Culbard B, Evans J, Gray NM, Ayansina D, Hubbard G. Vocational rehabilitation services for patients with cancer: design of a feasibility study incorporating a pilot randomised controlled trial among women with breast cancer following surgery. Trials. 2011;12:89-89.

29. Paterson C, Jones M, Rattray J, Lauder W. Identifying the self-management behaviours performed by prostate cancer survivors: a systematic review of the evidence. Journal of Research in Nursing. 2014;20(2):96-111.

30. Ream E, Quennell A, Fincham L, et al. Supportive care needs of men living with prostate cancer in England: a survey. British Journal of Cancer. 2008;98(12):1903-1909.

31. Breau RH, McGrath PJ, Norman RW. Assessing self-help issues for patients with prostate cancer, interstitial cystitis, erectile dysfunction and urinary diversion. BJU International. 2003;92(7):736-740.

32. Ettridge KA, Bowden JA, Chambers SK, et al. "Prostate cancer is far more hidden...”: Perceptions of stigma, social isolation and help-seeking among men with prostate cancer. European Journal of Cancer Care. 2017;27(2):e12790.

33. McKeon A, McCue M, Skidmore E, Schein M, Kulzer J. Ecological momentary assessment for rehabilitation of chronic illness and disability. Disability and Rehabilitation. 2018;40(8):974-987.

34. Aaron L, Turner J, Mancl L, Brister H, Sawchuk C. Electronic assessment of pain-related variables: Is reactivity a problem? The Journal of Pain. 2005;6:107-115.

35. Stone AA, Broderick JE, Schwartz JE, Shiffman S, Litcher-Kelly L, Calvanese P. Intensive momentary reporting of pain with an electronic diary: reactivity, compliance, and patient satisfaction. Pain. 2003;104(1-2):343-351.

36. Cruise CE, Broderick J, Porter L, Kaell A, Stone AA. Reactive effects of diary selfassessment in chronic pain patients. Pain. 1996;67(2-3):253-258. 
37. Litt MD, Cooney NL, Morse P. Ecological momentary assessment (EMA) with treated alcoholics: methodological problems and potential solutions. Health Psychology. 1998;17(1):48. 


\section{Table 1 Diary Structure Overview}

\begin{tabular}{|c|c|c|}
\hline Enquiry & Variables & Frequency \\
\hline Standard Entry & $\begin{array}{l}\text { Negative and positive affect } \\
\text { Coping (positive and negative) } \\
\text { Social support (perceived and received) } \\
\text { Self-management demand } \\
\text { Self-management control } \\
\text { Self-management self-efficacy }\end{array}$ & $\begin{array}{l}\text { Signal contingent: three } \\
\text { times per day, for a total of } \\
\text { one month }(n=93)\end{array}$ \\
\hline End of Day Entry & $\begin{array}{l}\text { Self-management behaviours (urinary, bowel and sexual } \\
\text { dysfunction) } \\
\text { Additional self-management behaviours } \\
\text { Self-management relief of symptoms } \\
\text { Self-efficacy } \\
\text { Satisfaction social support } \\
\text { Most demanding self-management action } \\
\text { Medication change } \\
\text { Quality of life }\end{array}$ & $\begin{array}{l}\text { Signal contingent: Once } \\
\text { per day, for a total of one } \\
\text { month }(n=31)\end{array}$ \\
\hline Incident Entry & $\begin{array}{l}\text { Description of participants challenging experience } \\
\text { Coping (positive and negative) } \\
\text { Perceived and received social support } \\
\text { Sought social support } \\
\text { Positive and negative affect }\end{array}$ & $\begin{array}{l}\text { Event contingent (any time } \\
\text { throughout one-month } \\
\text { period) }\end{array}$ \\
\hline
\end{tabular}




\section{Table 2 Interview Topic Guide}

- $\quad$ Can you describe in your own words your experience of having and completing the diary?

- How would you describe the experience of completing the diary to another prostate cancer patient?

- Can you describe how time consuming it was each day to complete the diary? Did this change over the month?

- $\quad$ Did the time you spent answering each question change over the month?

- Did you find some questions more relevant than others to your prostate cancer experience?

- $\quad$ Can you tell me about your support networks?

- Can you tell me about your self-care in the last month?

- Can you tell me about living with prostate cancer?

- Can you describe the impact of completing the diary on your daily life?

- Has completing the diary been a positive or negative experience for you?

- Has completing the diary made you think differently about: 1) coping, 2) support, 3) symptoms, 4) self-care, 5) how you are feeling, 6) your quality of life?

- Would you recommend other patients to complete the diary?

- Did you encounter any problems with completing the diary please describe?

- Any other comments that you feel are important? 
Table 3 Participant Characteristics

\begin{tabular}{|c|c|c|c|c|c|c|c|}
\hline $\begin{array}{l}\text { Participant and } \\
\text { social support }\end{array}$ & $\begin{array}{l}\text { Response } \\
\text { rate to } \\
\text { electronic } \\
\text { diary }^{\mathrm{a}}\end{array}$ & $\begin{array}{l}\text { Cancer stage and } \\
\text { treatment }\end{array}$ & Co-morbidity & Age & $\begin{array}{l}\text { Education (highest } \\
\text { qualification) }\end{array}$ & Employment & $\begin{array}{l}\text { Socio-economic } \\
\text { (SIMD } 1 \text { most } \\
\text { deprived - } 5 \text { least } \\
\text { deprived) }\end{array}$ \\
\hline $\begin{array}{l}\text { Mr A (100/31) } \\
\text { Partner } \\
\text { High self-report of } \\
\text { social support }\end{array}$ & $94.6 \%$ & $\begin{array}{l}\text { Localised prostate } \\
\text { cancer. Active } \\
\text { Surveillance }\end{array}$ & No & 73 & $\begin{array}{l}\text { Higher National } \\
\text { Certificate }\end{array}$ & Retired & 4 \\
\hline $\begin{array}{l}\text { Mr B (100/28) } \\
\text { Partner } \\
\text { Low self-report of } \\
\text { social support }\end{array}$ & $90.3 \%$ & $\begin{array}{l}\text { Localised prostate } \\
\text { cancer. Active } \\
\text { Surveillance }\end{array}$ & No & 61 & $\begin{array}{l}\text { Bachelor of Arts } \\
\text { Degree }\end{array}$ & Employed & 4 \\
\hline $\begin{array}{l}\text { Mr C (100/42) } \\
\text { Partner } \\
\text { High self-report of } \\
\text { social support }\end{array}$ & $87 \%$ & $\begin{array}{l}\text { Localised prostate } \\
\text { cancer. Laparoscopic } \\
\text { Radical } \\
\text { Prostatectomy }\end{array}$ & No & 51 & No qualification & Employed & 2 \\
\hline $\begin{array}{l}\text { Mr D (100/53) } \\
\text { Partner } \\
\text { High self-report of } \\
\text { social support }\end{array}$ & $97.7 \%$ & $\begin{array}{l}\text { Localised prostate } \\
\text { cancer. Laparoscopic } \\
\text { Radical } \\
\text { Prostatectomy }\end{array}$ & No & 59 & Trade qualification & Retired & 5 \\
\hline $\begin{array}{l}\text { Mr E (100/3) } \\
\text { Partner } \\
\text { High self-report of } \\
\text { social support }\end{array}$ & $97.9 \%$ & $\begin{array}{l}\text { Locally advanced } \\
\text { prostate cancer. } \\
\text { Radical Radiotherapy } \\
\text { and Androgen } \\
\text { Deprivation Therapy }\end{array}$ & No & 65 & Trade qualification & Retired & 4 \\
\hline $\begin{array}{l}\text { Mr F (100/5) } \\
\text { Partner } \\
\text { High self-report of } \\
\text { social support }\end{array}$ & $90.3 \%$ & $\begin{array}{l}\text { Locally advanced } \\
\text { prostate cancer. } \\
\text { Radical Radiotherapy } \\
\text { and Androgen } \\
\text { Deprivation Therapy }\end{array}$ & No & 57 & Trade qualification & Employed & 1 \\
\hline $\begin{array}{l}\text { Mr G (100/4) } \\
\text { Partner } \\
\text { Low self-report of } \\
\text { social support }\end{array}$ & $97.9 \%$ & $\begin{array}{l}\text { Locally advanced } \\
\text { prostate cancer. } \\
\text { Radical Radiotherapy } \\
\text { and Androgen } \\
\text { Deprivation Therapy }\end{array}$ & $\begin{array}{l}\text { Yes } \\
\text { Asthma, } \\
\text { Hypertension, } \\
\text { Depression. }\end{array}$ & 64 & $\begin{array}{l}\text { Higher National } \\
\text { Diploma }\end{array}$ & Retired & 4 \\
\hline $\begin{array}{l}\text { Mr H }(100 / 44) \\
\text { No partner } \\
\text { High self-report of } \\
\text { social support }\end{array}$ & $97.8 \%$ & $\begin{array}{l}\text { Locally advanced } \\
\text { prostate cancer. } \\
\text { Radical Radiotherapy } \\
\text { and Androgen } \\
\text { Deprivation Therapy }\end{array}$ & No & 73 & Trade qualification & Employed & 4 \\
\hline $\begin{array}{l}\text { Mr I (100/39) } \\
\text { No partner } \\
\text { Low self-report of } \\
\text { social support }\end{array}$ & $81.7 \%$ & $\begin{array}{l}\text { Locally advanced } \\
\text { prostate cancer. } \\
\text { Radical Radiotherapy } \\
\text { and Androgen } \\
\text { Deprivation Therapy }\end{array}$ & $\begin{array}{l}\text { Yes } \\
\text { Asthma } \\
\text { Hypertension }\end{array}$ & 73 & $\begin{array}{l}\text { Post-graduate Higher } \\
\text { National Diploma }\end{array}$ & Retired & 4 \\
\hline $\begin{array}{l}\text { Mr J 100/15 } \\
\text { Partner } \\
\text { Low self-report of } \\
\text { social support }\end{array}$ & $94.6 \%$ & $\begin{array}{l}\text { Metastatic disease. } \\
\text { Primary Androgen } \\
\text { Deprivation Therapy }\end{array}$ & No & 73 & A levels & Retired & 3 \\
\hline $\begin{array}{l}\text { Mr K 100/61 } \\
\text { Partner } \\
\text { High support }\end{array}$ & $91.3 \%$ & $\begin{array}{l}\text { Metastatic disease. } \\
\text { Primary Androgen } \\
\text { Deprivation Therapy }\end{array}$ & No & 72 & Trade qualification & Retired & 5 \\
\hline $\begin{array}{l}\text { Mr L (100/25) } \\
\text { Single } \\
\text { Low self-report of } \\
\text { social support }\end{array}$ & $\begin{array}{l}\text { Technical } \\
\text { error with } \\
\text { diary }\end{array}$ & $\begin{array}{l}\text { Metastatic disease. } \\
\text { Primary Androgen } \\
\text { Deprivation Therapy }\end{array}$ & $\begin{array}{l}\text { Yes } \\
\text { MI, Angina, } \\
\text { CVA, LTHR, } \\
\text { Hypertension. }\end{array}$ & 75 & Trade qualification & Retired & 5 \\
\hline
\end{tabular}

Abbreviations: MI, Myocardial Infarction; CVA, Cerebrovascular Accident; LTHR, Left Total Hip Replacement.

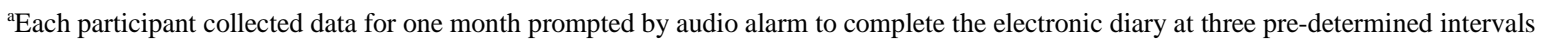
per day (totalling 93 data points). In addition, the participants could complete an incident entry at any time (24 hours a day) throughout the one-month period. 
Table 4 Lived Experienced Organising and Superordinate Themes

\begin{tabular}{|c|c|}
\hline Superordinate themes & Exemplar quotes \\
\hline Isolation in the healthcare system & $\begin{array}{l}\text { "Yeah, nothing has changed just the same really for self-care. The only time I seek support is when something goes wrong, but the issue is who do I go to to get the } \\
\text { support is the problem. But hopefully nothing else will go wrong." (Mr } \mathbf{D}) \\
\text { "The GP referred me to the hospital for clinical psychology. So that I could get psychological help, but when she came, she said that I will have to wait a long time for } \\
\text { that to take place, because there are very few members of staff relevant in the context to help. It was not just physical health reactions there were psychological and } \\
\text { emotional reactions as well." (Mr I) } \\
\text { "But I had no real information support to speak of. I have not really had all that much. Not in the official sense. It (completing the diary) made me think more about the } \\
\text { support I needed." (Mr I) }\end{array}$ \\
\hline Lack of shared care plans & $\begin{array}{l}\text { "Well I mean, I can’t get an erection anyway and I have seen the surgeon, there last week actually. He has put me on em, tablets these blue ones ... (pause) Viagra, just } \\
\text { to help with that, you know. I was actually, wanting the penis pump, you know as well, and em, he said, well this is how we start.” (Mr C) } \\
\text { "The main problem is getting up during the night which interrupts my sleeping, there must be a solution to that, and probably that is what is worrying me the most at the } \\
\text { moment. I just need to find a solution, you know, and I am always able to make it in time to go to the toilet. I know it is not that urgent to go but it is just, I waken up and } \\
\text { I know, that I have to go. I know the surgeon said, that he has a few tricks if needed, to stop me doing that, but em, I actually don't know what they are to be honest with } \\
\text { you.” (Mr D) } \\
\text { "I think, what has been most, and what will come out of the diary, it the hot flushes. This is the one (symptom), that at the end of the day (data entry), has been the worst } \\
\text { thing for me. I mean, de-dressing myself with the sweater, and then, putting it back on, then you are worried about having showers and the rest of it. Em, but, I mean } \\
\text { that was the main problem throughout. It was the hot flushes I wish I could get some help with managing them.” (Mr J) } \\
\text { "I do find them (healthcare professionals) a bit of doom mongers in here. I did speak with the surgeon and he thought it was time for business. He said, you are a } \\
\text { surgical candidate, and I thought, no no ... I am going to listen to myself. But I know is his business and that is what he is all about. That did not go down particularly } \\
\text { well, and I don't think that he meant to be like that, it was just, facts, facts, facts, facts, you know. You need to do something about this (cancer) em, this is what is going } \\
\text { to happen he said. No that did not appeal to me at all. Em ... I thought that could have been done in a better way.” (Mr B) }\end{array}$ \\
\hline Informational support & $\begin{array}{l}\text { "Informational, well there is no one that I can talk to about that, only read what I have been given in the book. So, I have not had anybody to tell me anything. I had the } \\
\text { little pamphlets, I read through them, and it tells you what you can expect, and what can go wrong. Ok, and so, it is just somebody to talk too, you know. (Mr H) } \\
\text { "You see Sam (gay partner) gives me support, both financial and emotional support, and em, as much as he can. It is not complete support. Informational would be } \\
\text { absolutely zilch (zero)." (Mr L) } \\
\text { "But I hope to get a communication from Mr X so I understand what is being done in relation to improving the pathway of treatment in the context of the hospital. I wish } \\
\text { they told me as getting information is very, very important for people with medical conditions. Important for understanding, and important for simply functioning and } \\
\text { coping." (Mr I) }\end{array}$ \\
\hline Coping with prostate cancer & $\begin{array}{l}\text { "I tried not to think about it, well bang, that it always, I always tried not to think about it.” (Mr A) } \\
\text { "getting information is very, very important for people with medical conditions. Important for understanding, and important for simply functioning and coping." (Mr I) } \\
\text { "I think that the most important thing is trying to remain positive, as I think that in the end it helps you to get through it you know. I mean em, sometimes you feel a bit } \\
\text { down and you think how are you going to get through this and em, maybe things are not going as well as you expected, but then you know, throughout time you did get } \\
\text { more positive, and hopefully the outcome will be successful, you know.” (Mr C) } \\
\text { "To put it in to words, when these little cells that my body have marshed, my mind would have focussed on it to help me down there, but em, I feel that it could be a } \\
\text { conceivable bad habit. In other words, it (cancer) could crop up elsewhere, and they (healthcare professionals) actually don’t know by examination, that it is happening } \\
\text { elsewhere. It is just, yes, it is like a bad habit the amount of the cells. As I understand of it, it belongs to me and not anyone else.” (Mr J) }\end{array}$ \\
\hline Fear of death and dying & $\begin{array}{l}\text { “When I was first told I had this prostate, and they have information for prostate cancer you know? But I was actually, petrified, as some of it said that prognosis is } 30 \% \text {, } \\
\text { so I didn’t read it, I was actually scared to be honest” (Mr F) } \\
\text { "Em also at the back of my mind, and put things in place, and I go into scenarios, with what if? What is going to happen to Helen and what's going to happen to the } \\
\text { children? (Mr I) }\end{array}$ \\
\hline
\end{tabular}




\begin{tabular}{|l}
\hline \\
"Another chap (patient) said em, what were your numbers, and I told him, and he said, oh my mate had that, and I said, oh is he doing fine, and he said no, he is dead! \\
Which is em, nobody meant it, I think that they were all suffering. So for me, I have stopped talking to other patients, it is not something that I would recommend.” (Mr \\
K) \\
"At the particular moment it is the urine function that impacts upon my work. I am doing the wheelchairs but I am not doing the trolly jobs. That is heavier, you know, \\
and would cause more stress on the bladder. Well, this is where I don't know how long I can go on with this, until this (incontinence) sorts itself out. This is the thing you \\
know, and my work, my supervisor is, em, the first week I was back was trying to push me into heavier things straight away. I said to him, you know I am not meant to \\
be doing that. On the first day I was back, I said, that I can only do light work, and he said to me, well you are not much help at all, I mean what do you take from that? \\
It’s no (not) my fault I got bloody cancer. As I say the urine problem is the biggest issue at the moment. I can deal with it OK at home, but it is really the work situation \\
that I need to try and manage.” (Mr C) \\
"This is where I find it really hard, when I have to sit back and do nothing. How do you get used to doing nothing? It is alright if you are in a normal 8-5 job or \\
something. Well, my day started 4-5 am in the morning, and finished 8-9pm at night. I was happy doing that you know, it is just like my life has came crashing down." \\
(Mr H)
\end{tabular}


Table 5 Electronic Diary as an Intervention Organising and Superordinate Themes

\begin{tabular}{|c|c|}
\hline Superordinate themes & Exemplar quotes \\
\hline Changing self-management behaviours & $\begin{array}{l}\text { “... it is my own attitude that I don’t speak to people. But I suppose it (electronic diary) makes me think that maybe I should (speak to people).” (Mr B) } \\
\text { “eh, probably actually a couple of weeks in to it (completing electronic diary), you know. To be honest, for the first little while, I never bother ticking that one, then all } \\
\text { of a sudden, I thought that I would try this decaffeinated (drinks) ones you know, and I have been using it since. It has helped me a bit.” (Mr C) } \\
\text { "Well some of them were positive in the sense that I discovered that, well I discovered techniques (self-care), that I could use. I would say that you can always extract } \\
\text { information from completing the diary” (Mr I) } \\
\text { "I had not really thought how can I help myself, on the bowel side should I pay more attention to my diet, em on the urinary side should I maybe not drink as much } \\
\text { wine?” (Mr J) }\end{array}$ \\
\hline Habitual experience & $\begin{array}{l}\text { "I suppose inevitably, em you take the questions for granted as you know the process that is the only danger I did notice, em, but you have a back button to go back. I } \\
\text { had to be careful not to skim over the questions. (Mr B) } \\
\text { "You will probably find that when I was putting my answers into the diary. I would say that is was a bit repetitive.” (Mr } \mathbf{D}) \\
\text { "Well obviously after a few days of having the diary I was aware of what questions were coming up in the diary. Or I thought I was aware of what questions were } \\
\text { coming up. Em [slight pause] I took my time initially, then I got blasé in making a few mistakes, not really making mistakes, but not putting in the answer I would have } \\
\text { done, so laterally I was paying attention as I would have done at the start.” (Mr E) } \\
\text { "At first, I took my time to read everything very, very carefully and then, after the first week, you know the sequence and you know what is coming up and you can just } \\
\text { answer it before it comes up. You are getting ready to press it before the question comes up. “(Mr G) } \\
\text { "Well I would say, the one roughly at 9pm was longer, but eventually and during that day it took me roughly } 5 \text { minutes. I always paid attention to the detail in the } \\
\text { questions" (Mr I) }\end{array}$ \\
\hline Changing perceptions & $\begin{array}{l}\text { "I think that the older you are, they would need to bring in a lot more support you know, like to change dressings and bags you know, the diary really showed me that it } \\
\text { could really be a lot worse for people you know, than it was for me doing self-care.” (Mr D) } \\
\text { "Well the diary did make my thoughts change, em, when I first started the treatment for my cancer, you know I knew it was going to affect me this way.” (Mr H) } \\
\text { "Going back to my earlier point, it has prompted me to be less blasé about everything, and it has prompted me to think about things a little more, and a little bit more } \\
\text { deeply about the problem that I have, and not to dismiss it, and not to think that it is all plain sailing. Quite thought provoking at times [Pause]” (Mr J) } \\
\text { "Because it made me realise after the radiotherapy was finished, it made me realize that I was tired, and as the diary was going on, it made me realize that I was tired and } \\
\text { if wasn't for the diary I would have not have known.” (Mr E) } \\
\text { "Well I didn't know about what some other poor souls have to put up with as I am very lucky I don't have any of that, and I have good support and no symptoms really.” } \\
\text { (Mr F) } \\
\text { "It is like having a diary and you put it down and share how you are feeling. It helped you analyse the problems and it helped you to realise that they were not as bad. So } \\
\text { it did help. When you set it down, it did help you know. I realise that I am doing fine. Instead of worrying about it.” (Mr K) }\end{array}$ \\
\hline Diary in daily life & $\begin{array}{l}\text { "The emotional and mood swings that people go through are significant. Perhaps, the electronic devise allows people to share experiences, without having to say, or } \\
\text { quantify things in a normal situation, a positive. It’s part of life to carry mobile technology around.” (Mr B) } \\
\text { "I think it was good, it was you know, it was trying to gain an understanding of what life is like for you. Routine is important, and it is different at different times of the } \\
\text { day, you know, so you need to capture that. Trying to pin point how people are coping at different times throughout the day. I found it interesting, you know just filling it } \\
\text { out. You know at different times throughout the day, you can, and you do feel differently. It is a very good thing." (Mr C) } \\
\text { "It amazing too, because I did think, how can I forget my problem when this thing keeps going off, in a few days you forgot it was there, amazing how quickly it became } \\
\text { part of your life. I would not have any hesitation in recommending this to another man.” (Mr E) } \\
\text { "Eh, I would take the diary with me on the Monday and Wednesday to my social club and my friends would say, is that your do-da going off again and I would say 'aye'. } \\
\text { (Mr F) }\end{array}$ \\
\hline
\end{tabular}


"if you are going out to a ruby match, oh you have got to say, oh right 3pm, but you can snooze it, em but you have really got to have the thing handy so you can make the entry. When I am driving I have to find a layby so I can make the entry by pulling in, but it's not too onerous that I would be frighten of, its just something that the more you do it, the more relaxed and confident you become in filling in the questions." (Mr $\mathbf{J}$ )

"I have learnt from completing the diary and actually I have been given a mobile phone as I was the last one in my family not to have one.” (Mr K) 
Lack of shared care plans

Informational support

Coping with prostate cancer

Lived experience

$\longrightarrow \quad$ Fear of death and dying

Men affected by

prostate cancer

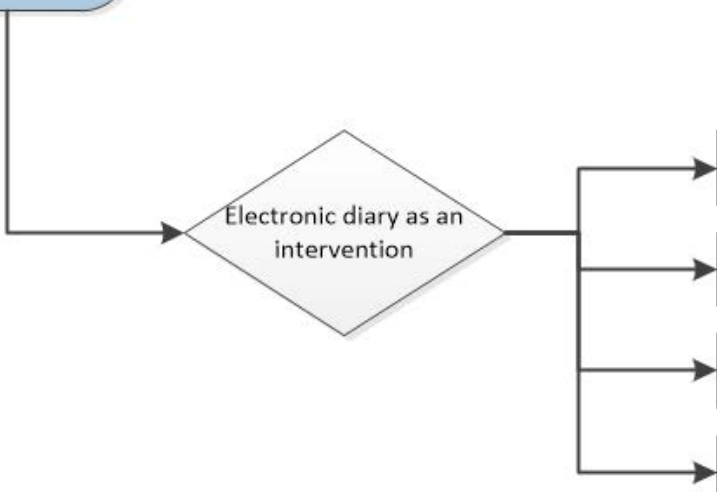

Changing self-management behaviours

Habitual experience

Changing perceptions

Diary in daily life

Figure. Coding structure derived from thematic analysis. 